\title{
Editorial: Short and sweet
}

\author{
Christopher H Knight* \\ University of Copenhagen Faculty of Medical Sciences, DK1870 Frb C, Denmark
}

This Editorial will be short, for a good reason. I believe that a story told concisely has more impact, and I encourage that in contributions to the Journal of Dairy Research. Modern research creates enormous amounts of data, and the desire to publish that data sometimes transcends the original research purpose. Data without purpose is worse than cheese without biscuits! The November issue of JDR will be the shortest since I became Editor, but our accepted articles are more numerous than ever before. Paradoxical? Not really: our output is constrained (we are a quarterly Journal with a prescribed annual page limit), but our input (submitted articles) is increasing in number and, I would argue, quality. Problematic? Not necessarily: our Supplementary File option has enabled a considerable reduction in article length (see Supplementary Table S1) and we shall encourage its greater use in future submissions. The guiding principle of good scientific publication is to report a hypothesis as supported or refuted through appropriate and repeatable methodology that yields statistically validated data. The article should always provide the proof and enough information to allow assessment of its veracity. Beyond that, modern publishing approaches allow greater flexibility: supportive data and detailed methodologies that enable repetition need not be part of the main article. A good scientific story can be well told in a minimum of text, or indeed in one notable case, no text at all (Upper, 1974). Those familiar with this citation (it dealt with writer's block) will recognise it as somewhat of a spoof, nevertheless, it has stood the test of time and has recently spawned a metaanalysis of the topic (McLean \& Thomas, 2014) that listed four other research studies reported in text length varying from 0 to 23 words. My message to you is this. No spoofs please, but brevity is strongly encouraged!
Short can be sweet, and this issue is no exception to that rule. More than 20 years ago, Journal of Dairy Research published a review of the properties of camel milk (Farah, 1993). An update is long overdue, and this issue provides an authoritative and futuristic one. Three articles then address hepatic metabolism, highlighting the problems faced by the high-yielding transition cow. A further three papers relate to mastitis control, including the thorny issue of prophylaxis on organic farms. Dairy products feature prominently, and the consumer is very much in mind, be it flavour compounds in Cheddar or bioactivities in yogurt. As is the case with most of what we do, 'consumer' is interpreted widely and our issue finishes with milk-derived peptides as antimicrobial additives for poultry feed. In the interests of brevity, none of these articles are cited here. To find them, simply go to Cambridge CORE, the new online platform for Cambridge University Press, and search for Journal of Dairy Research Volume 83, Issue 4.

\section{Supplementary material}

The supplementary material for this article can be found at https://doi.org/10.1017/S0022029916000698

\section{References}

Farah Z 1993 Composition and characteristics of camel milk Journal of Dairy Research 60 603-626

McLean DC \& Thomas BR 2014 Unsuccessful treatments of "Writer's Block": a meta-analysis. Psychological Reports: Relationships \& Communications 115 276-278

Upper D 1974 The unsuccessful self-treatment of a case of "writer's block". Journal of Applied Behavior Analysis 7497

*For correspondence; e-mail: chkn@sund.ku.dk 